\title{
Seroprevalence of fascioliasis, toxocariasis, strongyloidiasis and cysticercosis in blood samples diagnosed in Medic Medical Center Laboratory, Ho Chi Minh City, Vietnam in 2012
}

Toan Nguyen ${ }^{1+}$, Fei Wen Cheong ${ }^{2 \dagger}$, Jonathan Wee Kent Liew ${ }^{2+}$ and Yee Ling Lau ${ }^{2 *}$

\begin{abstract}
Background: Despite the global effort against neglected tropical diseases (NTDs), developing countries with middle to low income are still burdened by them. Vietnam has been undergoing substantial economic growth and urbanization, but underprivileged people living in rural and suburban areas are still having little access to public health infrastructure and proper sanitation. Hitherto, limited information is available for seroprevalence and risk factors of several parasitic diseases in Vietnam.

Methods: A retrospective study was performed on diagnostic results of Fasciola spp., Toxocara spp., Strongyloides stercoralis and Taenia solium IgG ELISA tests from Medic Medical Center Laboratory, Ho Chi Minh City in 2012. The data were first stratified before statistical analyses were performed. Seroprevalence of fascioliasis, toxocariasis, strongyloidiasis and cysticercosis was determined and the age and gender risk factors were evaluated.

Results: Seroprevalence of fascioliasis, toxocariasis, strongyloidiasis and cysticercosis was 5.9 \% (590/10,084; $95 \%$ Cl: 5.44-6.36), 45.2 \% (34,995/77,356; 95 \% Cl: 44.85-45.55), $7.4 \%$ (3,174/42,920; 95 \% Cl: 7.15-7.65) and 4.9 \% (713/14,601; $95 \%$ Cl: 4.55-5.25), respectively. Co-exposure to multiple parasites was detected in 890 males (45.7 \%; $95 \%$ Cl: 43.49-47.91) and 1,059 females (54.3\%; $95 \%$ Cl: 52.09-56.51). Social structure and differences in behavioural factors caused the gender factor to have a significant effect on the prevalence of all the diseases, while the seropositivity for fascioliasis and strongyloidiasis were age group-related.

Conclusions: The seroprevalence of fascioliasis, toxocariasis, strongyloidiasis and cysticercosis in the blood samples diagnosed in Medic Medical Center Laboratory, Ho Chi Minh City, in year 2012 were comparatively high. The Vietnamese customs and cultures, dietary habits and agricultural practices exposed them to high risk of contracting NTDs. Despite the possibility of false positive results due to antigenic cross-reactions, detection of IgG antibodies remains as a reliable method in sero-epidemiological study as it is non-invasive and demonstrates previous exposure of individuals to the parasites. Besides the implementation of strategies to control these diseases, epidemiological analysis and surveillance of diseases should also be continually strengthened to monitor the effectiveness of regimens and interventions.
\end{abstract}

(Continued on next page)

\footnotetext{
* Correspondence: lauyeeling@um.edu.my

${ }^{\dagger}$ Equal contributors

${ }^{2}$ Department of Parasitology, Tropical Infectious Diseases Research and

Education Center (TIDREC), Faculty of Medicine, University of Malaya, Kuala

Lumpur, Malaysia

Full list of author information is available at the end of the article
}

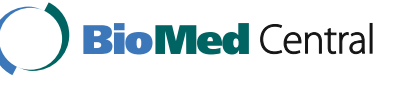

(c) 2016 The Author(s). Open Access This article is distributed under the terms of the Creative Commons Attribution 4.0 International License (http://creativecommons.org/licenses/by/4.0/), which permits unrestricted use, distribution, and reproduction in any medium, provided you give appropriate credit to the original author(s) and the source, provide a link to the Creative Commons license, and indicate if changes were made. The Creative Commons Public Domain Dedication waiver (http://creativecommons.org/publicdomain/zero/1.0/) applies to the data made available in this article, unless otherwise stated. 
(Continued from previous page)

Keywords: Seroprevalence, Fascioliasis, Toxocariasis, Strongyloidiasis, Cysticercosis, Southeast Asia

Abbreviations: $\mathrm{Cl}$, Confidence interval; DU, DRG units; ELISA, Enzyme-linked immunosorbent assay; HCMC, Ho Chi Minh City; Ig, Immunoglobulin; NIMPE, National Institute of Malariology, Parasitology and Entomology; NTDs, Neglected tropical diseases; OR, Odds ratio; RR, Relative risk; SDGs, United Nations Sustainable Development Goals; WHO, World Health Organization

\section{Background}

The global fight against neglected tropical diseases (NTDs) has continued to intensify with the adoption of the United Nations Sustainable Development Goals (SDGs) in 2015 [1]. These Global Goals seek, among others, to ensure healthy lives and access to water and sanitation for everyone, regardless of age. With these goals, we may only be one step away from the elimination of NTDs, which would then pave the way for the eradication of extreme global poverty, another goal of the SDGs. Neglected tropical diseases have always been correlated with poverty. While they cause morbidities worldwide, countries of low to middle income, where people live in poverty and have little access to sanitation, clean water and public healthcare, are most heavily burdened by these diseases.

Over the past two decades, Vietnam has made sound progress in the control of lymphatic filariasis and trachoma, besides achieving the World Health Organization (WHO) target of deworming $75 \%$ of school-aged children [2]. Nevertheless, more still needs to be done. The country has been experiencing remarkable economic growth and progress towards reducing poverty [3]. However, people from the rural areas and deprived inhabitants of the suburbs and peri-urban areas remain poor. Furthermore, most Vietnamese are employed in the agricultural, manufacturing, food processing and service sectors. Adding to that, the locals' customs, eating habits, agricultural practices and activities put them at a high risk of contracting NTDs [4]. In 2011, 148 outbreaks with 38,915 cases and 27 deaths due to food-borne disease were reported in Vietnam [5].

Various strategies have been put into place to control food-borne trematodiases, soil transmitted helminthiasis and parasitic zoonosis in the country. Continuous disease surveillance is therefore needed to track treatment impact and provide information on disease prevalence. Hitherto, several NTDs such as fascioliasis (caused by the liver flukes Fasciola spp.), taeniasis (caused by adult tapeworms Taenia spp.) and cysticercosis (caused by larvae of Taenia solium) are relatively well studied but there has been a lack of knowledge about the prevalence rates of other medically important parasitic diseases in Vietnam, especially toxocariasis (caused by the roundworms Toxocara spp.) and strongyloidiasis (caused by the threadworm Strongyloides stercoralis). In 2011, more than 20,000 cases of fascioliasis were reported in the central region of Vietnam [6, 7] while 229 out of 1,524 patients had cysticercosis, as reported by the National Institute of Malariology, Parasitology and Entomology (NIMPE) Clinic in 2010 [8]. Meanwhile, Toxocara spp. infection rates were reported to be $32.5 \%$ in the southern, $30.2 \%$ in the middle and $33.3 \%$ in the northern parts of Vietnam [9] whereas a $5 \%$ serological infection rate of S. stercoralis was detected in the Phu Cat district, Binh Dinh province in 2009 [10]. Information on infection rates and risks in specific groups of the population is clinically and epidemiologically important. Thus, we have retrospectively investigated the seroprevalence of fascioliasis, toxocariasis, strongyloidiasis and cysticercosis in blood samples tested in a diagnostic centre in the urban metropolis of Ho Chi Minh (HCMC), Vietnam, in the year 2012.

\section{Methods}

\section{Study setting}

The retrospective study was performed on diagnostic results of Fasciola spp., Toxocara spp., Strongyloides stercoralis and Taenia solium IgG ELISA tests from Medic Medical Center laboratory, HCMC, Vietnam in the year 2012. Medic Medical Center Laboratory is a reference diagnostic lab which receives blood samples from around the country, mostly from the city and the Mekong Delta region which lies west of the city. In year 2012, the average population number in HCMC and the Mekong Delta region was 7.66 million and 17.38 million, respectively [11]. Diagnostic tests were performed as requested by physicians albeit, a lesser number, by the patients who visited the lab.

Data were collected and analyzed anonymously. The anonymized data include all patients and individuals who took the tests from January to December 2012. Information collected consists of age, date of serum collection, gender and result of test. A total number of 10,084, $77,356,42,920$ and 14,601 individuals were tested with the Fasciola spp., Toxocara spp., Strongyloides stercoralis and Taenia solium IgG ELISA tests, respectively. Participants were categorized into groups according to gender (male/ female) and age group $(<1,1-15,16-30,31-45,46-60$, $61-75,76-90,>90$ year-old).

\section{Laboratory procedures}

All tests were performed by Medic Medical Center Laboratory using IgG ELISA kits according to the manufacturer's 
instructions. In all tests, absorbance was measured bichromatically at 450/620-650 nm. The Fasciola spp. IgG ELISA kit (DRG Instruments $\mathrm{GmbH}$, Marburg, Germany) utilizes immobilized Fasciola spp. antigen from adult liver fluke. Samples were considered positive if results showed a DU (DRG unit) of $>11$. The manufacturer reported a diagnostic sensitivity and specificity of $100 \%$. The Toxocara spp. IgG ELISA kit (DRG Instruments $\mathrm{GmbH}$, Springfield, USA) has the Toxocara spp. excretory antigen as the solid phase antigen. Positive samples show $\geq 0.3$ OD reading. The kit shows a concordance of $84 \%$, sensitivity of $87.5 \%$ and specificity of $93.3 \%$. The Strongyloides stercoralis IgG ELISA kit (DRG Instruments GmbH, Springfield, USA) uses microwells coated with Strongyloides L3 antigen. Samples were considered positive if results showed absorbance reading $\geq 0.2$ OD. The kit's performance is of $100 \%$ for both sensitivity and specificity. For serodiagnosis of cysticercosis, the Taenia solium IgG ELISA kit (DRG Instruments $\mathrm{GmbH}$, Springfield, USA) utilizes $T$. solium cyst fluid antigen for qualitative screening of serum IgG to T. solium. Samples with absorbance reading $\geq 0.3$ OD were considered positive. This test has a reported sensitivity of $87-88 \%$ and specificity of $96 \%$.

\section{Data analysis}

Statistical analyses was performed in the Department of Parasitology, University of Malaya, Malaysia using statistical package SPSS v.20 (SPSS IBM, US). Prior to analyses, the data were stratified according to gender (male/female) and age group in years $(\leq 60 />60)$. Pearson's Chi-square test was used in bivariate analysis to determine the association of disease seroprevalence with age and gender. Binary logistic regression analysis was performed in multivariable analysis to identify the significant risk factor variables and to control the confounders. Relative risk (RR), odds ratio (OR) and $95 \%$ confidence interval $(95 \% \mathrm{CI})$ were calculated, and the statistical significance level for all tests was set at $P<0.05$.

\section{Results}

The descriptive characteristics of participants according to gender and age group for fascioliasis, toxocariasis, strongyloidiasis and cysticercosis are presented in Table 1.

\section{Seroprevalence of fascioliasis}

Out of the 10,084 serum samples tested, 590 (5.9\%; $95 \%$ CI: 5.44-6.36) were positive for Fasciola spp. antibodies. Bivariate analysis was carried out to determine the association between seroprevalence with gender and age group (Table 2). Both variables were found to have statistically significant association with seroprevalence of fascioliasis. Lower prevalence was found in males compared to females (RR: $0.817 ; 95 \%$ CI: 0.70-0.96), and age group of $\leq 60$
Table 1 Descriptive characteristics of the participants

\begin{tabular}{|c|c|c|c|c|}
\hline \multirow[t]{2}{*}{ Characteristics } & $\begin{array}{l}\text { Fascioliasis } \\
(n=10,084)\end{array}$ & $\begin{array}{l}\text { Toxocariasis } \\
(n=77,356)\end{array}$ & $\begin{array}{l}\text { Strongyloidiasis } \\
(n=42,920)\end{array}$ & $\begin{array}{l}\text { Cysticercosis } \\
(n=14,601)\end{array}$ \\
\hline & $n(\%)$ & $n(\%)$ & $n(\%)$ & $n(\%)$ \\
\hline \multicolumn{5}{|l|}{ Gender } \\
\hline Male & $4,916(48.8)$ & $30,698(39.7)$ & $16,651(38.8)$ & $5,889(40.3)$ \\
\hline Female & $5,168(51.2)$ & $46,658(60.3)$ & $26,269(61.2)$ & $8,712(59.7)$ \\
\hline \multicolumn{5}{|c|}{ Age group (years) } \\
\hline$<1$ & $22(0.2)$ & $120(0.2)$ & $71(0.2)$ & $27(0.2)$ \\
\hline $1-15$ & $728(7.2)$ & $12,007(15.5)$ & $5,924(13.8)$ & $1,750(12.0)$ \\
\hline $16-30$ & $2,151(21.3)$ & $19,842(25.7)$ & $10,529(24.5)$ & $3,482(23.8)$ \\
\hline $31-45$ & $3,823(37.9)$ & $26,488(34.2)$ & $14,681(34.2)$ & $5,328(36.5)$ \\
\hline $46-60$ & $2,718(27.0)$ & $15,342(19.8)$ & $9,048(21.1)$ & $3,132(21.5)$ \\
\hline $61-75$ & $494(4.9)$ & 2,908 (3.8) & $2,089(4.9)$ & $695(4.8)$ \\
\hline $76-90$ & $140(1.4)$ & $627(0.8)$ & $545(1.3)$ & $175(1.2)$ \\
\hline$>90$ & $8(1.0)$ & $22(<0.1)$ & $33(0.1)$ & $12(0.1)$ \\
\hline
\end{tabular}

year-old exhibited a lower risk than age group of $>60$ yearold (RR: 0.719; 95 \% CI: 0.55-0.95). Multivariable logistic regression analysis (Table 3) detected the same pattern of association as bivariate analysis, where both risk factors were identified as significant predictors.

\section{Seroprevalence of toxocariasis}

A total of 34,995 out of 77,356 serum samples (45.2 \%; 95 \% CI: 44.85-45.55) were positive for Toxocara spp. antibodies. Bivariate analysis showed that gender was significantly associated with the seropositivity of toxocariasis (Table 2). Prevalence in males was slightly higher than in females, with a RR of 1.080 (95\% CI: 1.06-1.10). Binary logistic regression also yielded the same pattern of results, indicating that seroprevalence was significantly associated with gender but not age group (Table 3).

\section{Seroprevalence of strongyloidiasis}

Strongyloides stercoralis antibodies were detected in 3,174 of the 42,920 samples tested (7.4 \%; $95 \%$ CI: 7.15-7.65). Both univariate and multivariable analysis demonstrated that gender and age group were both significant risk factors for seroprevalence of strongyloidiasis (Tables 2 and 3). Results indicated that males had a higher risk of Strongyloides stercoralis infection than females (RR: 1.292; 95 \% CI: 1.21-1.38), while lower risk of infection was observed in age group of $\leq 60$ year-old than age group of > 60 year-old (RR: 0.635; $95 \%$ CI: $0.57-0.71$ ).

\section{Seroprevalence of cysticercosis}

Of the 14,601 serum samples, Taenia solium antibodies were detected in 713 samples (4.9\%; 95 \% CI: 4.55-5.25). Gender was the only statistically significant variable associated with cysticercosis in both Pearson's Chi-square test (Table 2) and binary logistic regression analysis (Table 3). 
Table 2 Univariate and bivariate analysis for the association between seroprevalence of diseases and risk factors

\begin{tabular}{|c|c|c|c|c|}
\hline Risk factor & $\begin{array}{l}\text { Fascioliasis } \\
n / \text { total } n(\%)\end{array}$ & $\begin{array}{l}\text { Toxocariasis } \\
n / \text { total } n(\%)\end{array}$ & $\begin{array}{l}\text { Strongyloidiasis } \\
n / \text { total } n(\%)\end{array}$ & $\begin{array}{l}\text { Cysticercosis } \\
\text { n/total n (\%) }\end{array}$ \\
\hline \multicolumn{5}{|l|}{ Gender } \\
\hline Male & 258/4,916 (5.2) & $14,533 / 30,698(47.3)$ & 1,429/16,651 (8.6) & $330 / 5,889(5.6)$ \\
\hline Female & $332 / 5,168(6.4)$ & 20,462/46,658 (43.9) & $1,745 / 26,269(6.6)$ & $383 / 8,712(4.4)$ \\
\hline RR & 0.817 & 1.080 & 1.292 & 1.275 \\
\hline$(95 \% \mathrm{Cl})$ & $(0.70-0.96)$ & $(1.06-1.10)$ & $(1.21-1.38)$ & $(1.10-1.47)$ \\
\hline$P$-value & 0.012 & $<0.0001$ & $<0.0001$ & 0.001 \\
\hline \multicolumn{5}{|c|}{ Age group (years) } \\
\hline$\leq 60$ & $539 / 9,442(5.7)$ & $33,363 / 73,799(45.2)$ & 2,874/40,253 (7.1) & $659 / 13,719(4.8)$ \\
\hline$>60$ & $51 / 642(7.9)$ & 1,632/3,557 (45.9) & $300 / 2,667$ (11.2) & $54 / 882(6.1)$ \\
\hline RR & 0.719 & 0.985 & 0.635 & 0.785 \\
\hline$(95 \% \mathrm{Cl})$ & $(0.55-0.95)$ & $(0.95-1.02)$ & $(0.57-0.71)$ & $(0.60-1.03)$ \\
\hline$P$-value & 0.020 & 0.431 & $<0.0001$ & 0.078 \\
\hline
\end{tabular}

Of that, higher seroprevalence of cysticercosis was found in males (RR: 1.275; 95 \% CI: 1.10-1.47), whereas age group of $\leq 60$ year-old had a lower risk of infection than age group of $>60$ year-old (RR: 0.785; 95 \% CI: 0.60-1.03).

\section{Co-exposure rate}

Table 4 summarizes the seroprevalence of co-exposure to fascioliasis, toxocariasis, strongyloidiasis and cysticercosis. Co-exposure to multiple parasites was detected in 890 males (45.7\%; $95 \%$ CI: 43.49-47.91) and 1,059 females (54.3\%; $95 \%$ CI: 52.09-56.51). Among them, co-exposure to strongyloidiasis and toxocariasis was the most prevalent $(1,362 / 1,949,69.9 \%$; $95 \%$ CI: $67.86-$ $71.94)$, followed by that of cysticercosis and toxocariasis (211/1,949, $10.8 \%$; 95 \% CI: 9.42-12.18) and cysticercosis and strongyloidiasis $(110 / 1,949,5.6 \%$; $95 \%$ CI: $4.58-$ 6.62). Five persons ( $0.3 \%$; $95 \% \mathrm{CI}: 0.06-0.54)$ were found to be seropositive for antibodies against all of the four helminths. A total of $36.8 \%, 26.4 \%$ and $17.9 \%$ of the co-exposures occurred in 31-45 year-old (718/1,949; $95 \%$ CI: 34.66-38.94), 46-60 year-old (515/1,949; 95 \% CI: 24.44-28.36) and 16-30 year-old (348/1,949; $95 \%$ CI: 16.20-19.60) patients, respectively.

\section{Discussion}

Little information is available on the prevalence of parasitic infections in Vietnam especially on toxocariasis and strongyloidiasis. The seroprevalence rates found in this study may reflect that of people living in the southwest region of Vietnam, including HCMC, as most of the blood samples received originated from this region. Seroprevalence rates for all infections reported here are high, especially for toxocariasis (45.2\%) and strongyloidiasis (7.4\%). Transmission of some of the diseases can be explained by the dietary habits of the locals. For example, consuming raw vegetables such as kangkong-kalabau (Enhydra fluctuants) and Brahmi (Herpestis monniera) contaminated with metacercariae of Fasciola spp., or eating raw/pickled pork (nem chua and nem chao), vegetables and dog meat contaminated with taeniid eggs and cysts of $T$. solium $[12,13]$. Besides, proximity with infected livestock, use of human faeces as fertilizer, poor sanitation and others, further increase disease transmission to humans $[5,14,15]$.

In Vietnam, fascioliasis is caused by Fasciola gigantica and the hybrid of Fasciola hepatica and Fasciola gigantica [16]. This emerging food-borne trematodiasis $[5,17]$ is transmitted in most of the provinces in Vietnam,

Table 3 Multivariable analysis for the association between seroprevalence of diseases and risk factors

\begin{tabular}{|c|c|c|c|c|}
\hline \multirow[t]{2}{*}{ Risk factor } & Fascioliasis & Toxocariasis & Strongyloidiasis & Cysticercosis \\
\hline & OR (95 \% Cl) & OR $(95 \%$ Cl) & OR $(95 \% \mathrm{Cl})$ & OR (95 \% Cl) \\
\hline \multicolumn{5}{|l|}{ Gender } \\
\hline Male/female & $0.814(0.69-0.96)$ & $1.152(1.12-1.19)$ & $1.330(1.24-1.43)$ & $1.297(1.12-1.51)$ \\
\hline$P$-value & 0.016 & $<0.0001$ & $<0.0001$ & 0.001 \\
\hline \multicolumn{5}{|c|}{ Age group (years) } \\
\hline$\leq 60 />60$ & $0.715(0.53-0.96)$ & $0.964(0.90-1.03)$ & $0.597(0.53-0.68)$ & $0.761(0.57-1.01)$ \\
\hline$P$-value & 0.028 & 0.283 & $<0.0001$ & 0.062 \\
\hline
\end{tabular}


Table 4 Seroprevalence of co-exposure to fascioliasis, toxocariasis, strongyloidiasis and cysticercosis

\begin{tabular}{|c|c|c|c|c|c|c|c|c|c|c|c|c|c|}
\hline \multicolumn{2}{|c|}{ Risk factor } & \multirow{2}{*}{$\begin{array}{l}F+S \\
n(\%)\end{array}$} & \multirow{2}{*}{$\begin{array}{l}F+T \\
n(\%)\end{array}$} & \multirow{2}{*}{$\begin{array}{l}C+T \\
n(\%)\end{array}$} & \multirow{2}{*}{$\begin{array}{l}S+T \\
n(\%)\end{array}$} & \multirow{2}{*}{$\begin{array}{l}C+S \\
n(\%)\end{array}$} & \multirow{2}{*}{$\begin{array}{l}C+F \\
n(\%)\end{array}$} & \multirow{2}{*}{$\begin{array}{l}F+S+T \\
n(\%)\end{array}$} & \multirow{2}{*}{$\begin{array}{l}F+S+C \\
n(\%)\end{array}$} & \multirow{2}{*}{$\begin{array}{l}\mathrm{C}+\mathrm{T}+\mathrm{S} \\
n(\%)\end{array}$} & \multirow{2}{*}{$\begin{array}{l}C+T+F \\
n(\%)\end{array}$} & \multirow{2}{*}{$\begin{array}{l}F+S+C+T \\
n(\%)\end{array}$} & \multirow{2}{*}{$\begin{array}{l}\text { Total } \\
n(\%)\end{array}$} \\
\hline Gender & Age group & & & & & & & & & & & & \\
\hline \multirow[t]{8}{*}{ Male } & $<1$ & $1(3.7)$ & $0(0.0)$ & $0(0.0)$ & $1(0.1)$ & $1(0.9)$ & $0(0.0)$ & $0(0.0)$ & $0(0.0)$ & $0(0.0)$ & $0(0.0)$ & $0(0.0)$ & 3 \\
\hline & $1-15$ & $2(7.4)$ & $2(1.9)$ & $52(24.6)$ & $46(3.4)$ & $8(7.3)$ & $0(0.0)$ & $0(0.0)$ & $0(0.0)$ & $6(5.7)$ & $0(0.0)$ & $0(0.0)$ & 116 \\
\hline & $16-30$ & $1(3.7)$ & $6(5.6)$ & $17(8.1)$ & $106(7.8)$ & $6(5.5)$ & $1(33.3)$ & $3(20.0)$ & $0(0.0)$ & $9(8.5)$ & $0(0.0)$ & $0(0.0)$ & 149 \\
\hline & $31-45$ & $6(22.2)$ & $23(21.5)$ & $23(10.9)$ & $232(17.0)$ & $14(12.7)$ & $0(0.0)$ & $1(6.7)$ & $0(0.0)$ & $16(15.1)$ & 1 (100.0) & $0(0.0)$ & 316 \\
\hline & $46-60$ & $2(7.4)$ & 17 (15.9) & $10(4.7)$ & $163(12.0)$ & 15 (13.6) & $0(0.0)$ & $2(13.3)$ & $1(50.0)$ & $7(6.6)$ & $0(0.0)$ & $1(20.0)$ & 218 \\
\hline & $61-75$ & $0(0.0)$ & $3(2.8)$ & $2(0.9)$ & $51(3.7)$ & $5(4.5)$ & $0(0.0)$ & $0(0.0)$ & $0(0.0)$ & $7(6.6)$ & $0(0.0)$ & $1(20.0)$ & 69 \\
\hline & $76-90$ & $0(0.0)$ & $0(0.0)$ & $1(0.5)$ & $17(1.2)$ & $0(0.0)$ & $0(0.0)$ & $0(0.0)$ & $0(0.0)$ & $1(0.9)$ & $0(0.0)$ & $0(0.0)$ & 19 \\
\hline & $>90$ & $0(0.0)$ & $0(0.0)$ & $0(0.0)$ & $0(0.0)$ & $0(0.0)$ & $0(0.0)$ & $0(0.0)$ & $0(0.0)$ & $0(0.0)$ & $0(0.0)$ & $0(0.0)$ & 0 \\
\hline \multirow[t]{8}{*}{ Female } & $<1$ & $0(0.0)$ & $0(0.0)$ & $0(0.0)$ & $2(0.1)$ & $0(0.0)$ & $0(0.0)$ & $0(0.0)$ & $0(0.0)$ & $0(0.0)$ & $0(0.0)$ & $0(0.0)$ & 2 \\
\hline & $1-15$ & $1(3.7)$ & $1(0.9)$ & $14(6.6)$ & $50(3.7)$ & $3(2.7)$ & 1 (33.3) & $1(6.7)$ & $0(0.0)$ & $2(1.9)$ & $0(0.0)$ & $0(0.0)$ & 73 \\
\hline & $16-30$ & $5(18.5)$ & $13(12.1)$ & $21(10.0)$ & $141(10.4)$ & $9(8.2)$ & $0(0.0)$ & $2(13.3)$ & $0(0.0)$ & $8(7.5)$ & $0(0.0)$ & $0(0.0)$ & 199 \\
\hline & $31-45$ & $7(25.9)$ & 22 (20.6) & $40(19.0)$ & $284(20.9)$ & 19 (17.3) & 1 (33.3) & $2(13.3)$ & $1(50.0)$ & $26(24.5)$ & $0(0.0)$ & $0(0.0)$ & 402 \\
\hline & $46-60$ & $1(3.7)$ & 14 (13.1) & 29 (13.7) & $210(15.4)$ & 26 (23.6) & $0(0.0)$ & $2(13.3)$ & $0(0.0)$ & $13(12.3)$ & $0(0.0)$ & $2(40.0)$ & 297 \\
\hline & $61-75$ & $0(0.0)$ & $5(4.7)$ & $1(0.5)$ & $48(3.5)$ & $2(1.8)$ & $0(0.0)$ & $2(13.3)$ & $0(0.0)$ & $9(8.5)$ & $0(0.0)$ & $1(20.0)$ & 68 \\
\hline & $76-90$ & $1(3.7)$ & $1(0.9)$ & $1(0.5)$ & $9(0.7)$ & $2(1.8)$ & $0(0.0)$ & $0(0.0)$ & $0(0.0)$ & $2(1.9)$ & $0(0.0)$ & $0(0.0)$ & 16 \\
\hline & $>90$ & $0(0.0)$ & $0(0.0)$ & $0(0.0)$ & $2(0.1)$ & $0(0.0)$ & $0(0.0)$ & $0(0.0)$ & $0(0.0)$ & $0(0.0)$ & $0(0.0)$ & $0(0.0)$ & 2 \\
\hline Total & & 27 & 107 & 211 & 1,362 & 110 & 3 & 15 & 2 & 106 & 1 & 5 & 1,949 \\
\hline
\end{tabular}

Abbreviations: $F$ fascioliasis, $T$ toxocariasis, $S$ strongyloidiasis, $C$ cysticercosis

particularly in the central regions [18] with an overall anti-Fasciola spp. IgG seroprevalence of $7.8 \%$ among adult cohorts in two central provinces of Vietnam in 2013 [19]. In this study, a $5.9 \%$ seroprevalence of fascioliasis was detected, which is in accordance with the World Health Organization [20] report stating that prevalence can reach a high $5.4 \%$ at endemic foci. This suggests that not only the central region, but other regions of the country may pose a high seroprevalence of fascioliasis too. In endemic foci, infected patients are usually women aged between 17 and 45 years; also in some areas, the number of infected women are about three times the number of infected men $[6,20,21]$. In our study, females aged between 16 and 45 years constituted one third of the total exposure rate $(31.7 \%)$. Females may face a higher exposure rate to water and freshwater plants that carry metacercariae, as they are responsible for household chores.

Toxocariasis is commonly transmitted by accidental swallowing of soil contaminated with Toxocara spp.eggs. In the present study, a seroprevalence of $45.2 \%$ was detected for toxocariasis, higher than the reported infection rates of $30.2-33.3 \%$ in parts of Vietnam [9]. Seroprevalence of toxocariasis in Vietnam appears to be one of the highest in the world when compared with that of other countries [22-26]. Contacts with Toxocara-infected cats and dogs is one of the main factors for human toxocariasis transmission. A recent study in 2014 showed high toxocariasis prevalence in household cats $(47.8 \%)$ and dogs $(37.7 \%)$ in Hanoi city, Vietnam, which partly contributed to the finding of anti-Toxocara IgG antibodies in $58.7 \%$ of the human samples. Moreover, the high egg excretion rates of infected dogs or cats, along with the large numbers of free roaming stray animals increase contamination of soil and vegetables with Toxocara spp. eggs [27], leading to higher transmission rate. Males were found to have greater exposure to toxocariasis than females, similar to other findings [26, 28-31]. Previous studies also found that prevalence of toxocariasis is significantly higher in children due to their geophagia, playing and social behaviours, which is in disagreement with our finding and another study [25] that age group is not a significant association factor. Deworming household pets, proper hygiene, adequate cooking of food and education to the public [32] are some measures that can be taken to reduce the high levels of Toxocara spp. infection in the country.

Infection with Strongyloides stercoralis is endemic in many tropical and subtropical countries [33]. Even so, there is limited data on infection rates of $S$. stercoralis in Vietnam. Our study revealed $7.4 \%$ seropositivity for strongyloidiasis, which is slightly lower than that in the neighbouring southeast Asian countries of Cambodia (17.5\%), Lao PDR (26.2 \%), and Thailand (23.7 \%) [34]. A prevalence study in Vietnam had detected a $5 \%$ serological infection rate of $S$. stercoralis in the Phu Cat district, Binh Dinh province in 2009 [10]. Humans become infected through contact with Strongyloides larvae-contaminated 
soil, while playing or working barefoot on the ground. Similar to other studies conducted in Thailand [35] and Cambodia [36], a higher rate of S. stercoralis infection in men than in women was found in this study. This is most likely due to males working outdoors, barefooted while the females usually work at home and have the habit of wearing shoes when walking on the ground [35].

Cysticercosis develops in human hosts who have ingested soil, water or food contaminated with the eggs of the pork tapeworm Taenia solium [5]. The 2014 prevalence of cysticercosis in northern and southern Vietnam was $1.0-7.2 \%$ and $4.3 \%$, respectively [8]. The $4.9 \%$ prevalence of cysticercosis found in the present study is in agreement with the above reports. The gender risk factor for cysticercosis infection could be explained by the social structure of Vietnam. In Vietnam, males have the primary role of supporting and sustaining the family by working outdoors, increasing their exposure rate to Taeniacontaminated sources. Willingham et al. [37] reported that $70 \%$ of cysticercosis patients seen at hospitals were male. As in the present study, several seroprevalence studies have also revealed that seropositivity for cysticercosis is not significantly related to age group [38-41].

In our study, 1,949 individuals from among those seropositive for the tested parasites were also positive for more than one parasite. In fact, in 2011, more than $60 \%$ of infected cases in Vietnam were found to have two to five kinds of parasites [7]. Studies done in Southern Laos [42] and on urban dwellers in Ethiopia [43] show that polyparasitism is very common $(52.4 \%$ and $56.7 \%$, respectively). It was found that co-exposure to toxocariasis and strongyloidiasis was the most prevalent. It is possibly due to the highest prevalence of the two diseases among the four NTDs, shared routes of transmission such as soil and the parasites co-existence in the environment. However, the co-exposure rates should also be interpreted with care. It has been evident that cross-reactions often happen in ELISA-based serological tests, leading to false positive results. Cross-reactions with Strongyloides, Fasciola, Ascaris, Schistosoma spp. and other parasites were reported when excretory/secretory (E/S) antigen from second-stage larvae of Toxocara canis was used in ELISA [44, 45]. Use of $S$. stercoralis filariform/L3 larvae antigen in ELISA was shown to be $\geq 88 \%$ sensitive and $\geq 96.1 \%$ specific in detecting specific anti-IgG, with possible cross-reaction with toxocariasis, Ascaris lumbricoides and others [46, 47].

A positive IgG serodiagnosis can be caused by any residual antibodies after successful treatment or an ongoing, chronic infection. However, ELISA-based serological tests rather than parasitological methods are preferred due to the better specificity and sensitivity [6]. Serological test to detect specific IgG, not IgM or IgA, is recommended for most parasitic diseases [48]. Therefore, detection of IgG antibodies in this sero-epidemiological study is deemed appropriate and demonstrates exposure of individuals to the parasites. Nonetheless, the authors agree that accurate diagnosis should be done in conjunction with other clinical findings, epidemiological factors and other laboratory results. The current study would benefit from stool studies to determine active infection, complementing the serological test results.

\section{Conclusions}

The overall IgG seroprevalence rates against the parasites were found to be relatively high (fascioliasis, $5.9 \%$; toxocariasis, $45.2 \%$; strongyloidiasis, 7.4\%; cysticercosis, $4.9 \%$ among individuals diagnosed in the Medic Medical Center Laboratory, Ho Chi Minh City throughout the year 2012. Analyses revealed that females are more exposed to Fasciola spp. while men have significant risks of toxocariasis, strongyloidiasis and cysticercosis. Furthermore, people older than 60 years showed a significant higher risk of being infected with fascioliasis and strongyloidiasis. The four parasitic diseases investigated in this retrospective study are environment-related parasitic infections. Therefore, proper hygiene and sanitation must be observed in order to control the diseases. The current study also highlighted epidemiological data of strongylodiasis and toxocariasis in Vietnam, which are scarce in the region. Continual epidemiological analysis and food-borne zoonosis surveillance should be carried out in order to monitor the effectiveness of the regimens employed and also to revamp or implement more successful interventions.

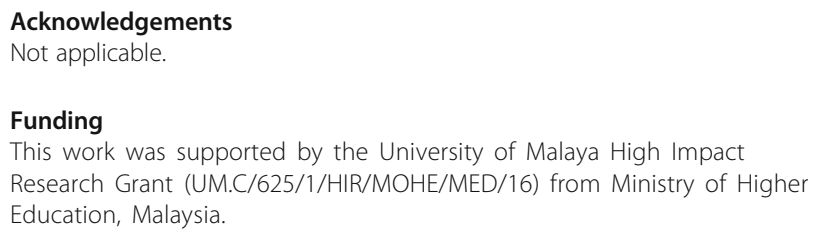

Availability of data and material

The datasets supporting the conclusions of this article are included within the article.

\section{Authors' contributions \\ YLL conceived and designed the study. TN obtained and performed diagnostic tests. JWKL and FWC analyzed the data and drafted the manuscript. All authors read and approved the final manuscript.}

\section{Competing interests}

The authors declare that they have no competing interests.

\section{Consent for publication}

Not applicable.

\section{Ethics approval and consent to participate}

Approval for this study was obtained from the Medical Ethics Committee of University of Malaya Medical Center, Malaysia (MECID. NO: 20158-1564).

\section{Author details}

${ }^{1}$ Medic Medical Center Laboratory, Ho Chi Minh City, Vietnam. ${ }^{2}$ Department of Parasitology, Tropical Infectious Diseases Research and Education Center (TIDREC), Faculty of Medicine, University of Malaya, Kuala Lumpur, Malaysia. 


\section{Received: 13 June 2016 Accepted: 29 August 2016}

\section{Published online: 05 September 2016}

\section{References}

1. United Nations. In: Transforming our world: the 2030 agenda for sustainable development. 2015. https://sustainabledevelopment.un.org/content/ documents/21252030\%20Agenda\%20for\%20Sustainable\%20 Development\%20web.pdf. Accessed 10 June 2016

2. World Health Organization. Regional action plan for neglected tropica diseases in the Western Pacific Region (2012-2016). 2013. http://www. wpro.who.int/mvp/documents/docs/regional_action_plan_for_ntd.pdf. Accessed 10 June 2016.

3. World Bank: Vietnam. http://www.worldbank.org/en/country/vietnam. Accessed 8 June 2016

4. Hotez PJ, Bottazzi ME, Strych U, Chang LY, Lim YAL, Goodenow MM, et al. Neglected tropical diseases among the Association of Southeast Asian Nations (ASEAN): Overview and update. PLoS Negl Trop Dis. 2015;9(4), e0003575.

5. Carrique-Mas JJ, Bryant JE. A review of foodborne bacterial and parasitic zoonoses in Vietnam. Ecohealth. 2013;10(4):465-89.

6. Bui TD, Doanh PN, Saegerman C, Losson B. Current status of fasciolosis in Vietnam: an update and perspectives. J Helminthol. 2015;1-12.

7. Institute of Malariology, Parasitology and Entomology - Quy Nhon: Situation of fascioliasis and intestinal parasitic diseases in first 5 months of 2011. http://www.impe-qn.org.vn/impe-qn/en/portal//nfoDetail. jsp?area $=58 \&$ cat $=1067 \& \mid \mathrm{D}=617$. Accessed 10 June 2016.

8. Van De N, Le TH, Lien PT, Eom KS. Current status of taeniasis and cysticercosis in Vietnam. Korean J Parasitol. 2014;52(2):125-9.

9. Vd N, Nguyen VT, Le Van D, Chai JY. Molecular diagnosis of an ocular toxocariasis patient in Vietnam. Korean J Parasitol. 2013;51(5):563-7.

10. Institute of Malariology, Parasitology and Entomology - Quy Nhon: Disease control activities of IMPE-Quy Nhon in first 10 months of 2009. http://www.impe-qn.org.vn/impe-qn/en/portal//nfoPreview.jsp?ID=527. Accessed 10 June 2016

11. General Statistics Office of Vietnam: Statistical data: Population and employment. http://www.gso.gov.vn/default_en.aspx?tabid=774. Accessed 15 July 2016

12. Uga S, Hoa NT, Noda S, Moji K, Cong L, Aoki Y, et al. Parasite egg contamination of vegetables from a suburban market in Hanoi, Vietnam. Nepal Med Coll J. 2009;11(2):75-8.

13. Willingham III AL, Wu HW, Conlan J, Satrija F. Combating Taenia solium cysticercosis in Southeast Asia an opportunity for improving human health and livestock production. Adv Parasitol. 2010;72:235-66.

14. Bui KL, Do TT, Le NM, Osamu S, Shinobu Y. Application of agar gel diffusion test to the diagnosis of fasciolosis in cattle and buffaloes in the Red River delta in Vietnam. Jpn Agr Res Quart. 2003:37:201-5.

15. Dorny P, Somers R, Cam Thi Dang T, Khong Nguyen V, Vercruysse J. Cysticercosis in Cambodia, Lao PDR and Vietnam. Southeast Asian J Trop Med Public Health. 2004;35:223-6.

16. Le TH, De NV, Agatsuma T, Thi Nguyen TG, Nguyen QD, McManus DP, et al. Human fascioliasis and the presence of hybrid/introgressed forms of Fasciola hepatica and Fasciola gigantica in Vietnam. Int J Parasitol. 2008;38(6):725-30

17. World Health Organization. In: Report of the WHO Informal Meeting on use of triclabendazole in fascioliasis control. 2006. http://www.who.int/neglected_ diseases/preventive_chemotherapy/WHO_CDS_NTD_PCT_2007.1.pdf. Accessed 10 June 2016

18. Tran VH, Tran TK, Nguye HC, Pham HD, Pham TH. Fascioliasis in Vietnam. Southeast Asian J Trop Med Public Health. 2001;32 Suppl 2:48-50.

19. Quy TM, Yeatman H, Flood VM, Chuong NC, Tuan BV. Prevalence and risks of fascioliasis among adult cohorts in Binh Dinh and Quang Ngai provinces central Viet Nam. Vietnam J Public Health. 2015;3(1):46-61.

20. World Health Organization. In: Report of the WHO expert consultation on foodborne trematode infections and taeniasis/cysticercosis. 2009. http://www.who.int/neglected_diseases/preventive_chemotherapy/WHO HTM_NTD_PCT_2011.3.pdf. Accessed 10 June 2016.

21. Esteban JG, Gonzalez C, Curtale F, Munoz-Antoli C, Valero MA Bargues MD, et al. Hyperendemic fascioliasis associated with schistosomiasis in villages in the Nile Delta of Egypt. Am J Trop Med Hyg. 2003;69(4):429-37.
22. Fenoy S, Cuellar C, Guillen JL. Seroprevalence of toxocariasis in children and adults in Madrid and Tenerife, Spain. J Helminthol. 1996;70(2):109-13.

23. Iddawela DR, Kumarasiri PV, de Wijesundera MS. A seroepidemiological study of toxocariasis and risk factors for infection in children in Sri Lanka. Southeast Asian J Trop Med Public Health. 2003;34(1):7-15.

24. Kim YH, Huh S, Chung YB. Seroprevalence of toxocariasis among healthy people with eosinophilia. Korean J Parasitol. 2008;46(1):29-32.

25. El-Shazly AM, Abdel Baset SM, Kamal A, Mohammed KA, Sakrs TI, Hammad SM. Seroprevalence of human toxocariasis (visceral larva migrans). J Egypt Soc Parasitol. 2009;39(3):731-44.

26. Fu CJ, Kao CY, Lee YL, Liao CW, Chen PC, Chuang TW, et al. Seroprevalence and associated risk factors of toxocariasis among college students in Taipei City, Taiwan. Iran J Parasitol. 2015;10(3):482-9.

27. Anh NT, Thuy DT, Hoan DH, Hop NT, Dung DT. Levels of Toxocara infections in dogs and cats from urban Vietnam together with associated risk factors for transmission. J Helminthol. 2016;90(4):508-10.

28. Dar ZA, Tanveer S, Yattoo GN, Sofi BA, Wani SA, Dar PA. Seroprevalence of toxocariasis in children in Kashmir, J\&K State, India. Iran J Parasitol. 2008:3(4):45-50.

29. Espinoza YA, Huapaya PH, Roldan WH, Jimenez S, Arce Z, Lopez E. Clinical and serological evidence of Toxocara infection in school children from Morrope district, Lambayeque, Peru. Rev Inst Med Trop Sao Paulo. 2008;50(2):101-5.

30. Won KY, Kruszon-Moran D, Schantz PM, Jones JL. National seroprevalence and risk factors for zoonotic Toxocara spp. infection. Am J Trop Med Hyg. 2008;79(4):552-7.

31. Romano N, Nor Azah MO, Rahmah N, Lim YAL, Rohela M. Seroprevalence of toxocariasis among Orang Asli (Indigenous people) in Malaysia using two immunoassays. Trop Biomed. 2010;27(3):585-94.

32. Macpherson CN. The epidemiology and public health importance of toxocariasis: a zoonosis of global importance. Int J Parasitol. 2013:43(12-13):999-1008.

33. Cimino RO, Krolewiecki A. The epidemiology of human strongyloidiasis. Cur Trop Med Rep. 2014;1(4):216-22.

34. Schar F, Trostdorf U, Giardina F, Khieu V, Muth S, Marti H, et al. Strongyloides stercoralis: Global distribution and risk factors. PLoS Negl Trop Dis. 2013;7(7), e2288.

35. Nontasut P, Muennoo C, Sa-nguankiat S, Fongsri S, Vichit A. Prevalence of Strongyloides in Northern Thailand and treatment with ivermectin vs albendazole. Southeast Asian J Trop Med Public Health. 2005;36(2):442-4.

36. Khieu V, Schär F, Marti H, Bless PJ, Char MC, Muth S, et al. Prevalence and risk factors of Strongyloides stercoralis in Takeo Province, Cambodia. Parasit Vectors. 2014;7:221.

37. Willingham III AL, De NV, Doanh NQ, le Cong D, Dung TV, Dorny P, et al. Current status of cysticercosis in Vietnam. Southeast Asian J Trop Med Public Health. 2003;34 Suppl 1:35-50

38. Xu JM, Acosta LP, Hou M, Manalo DL, Jiz M, Jarilla B, et al. Seroprevalence of cysticercosis in children and young adults living in a helminth endemic community in leyte, the Philippines. J Trop Med. 2010;2010:603174.

39. Adjide CC, Bouteille B, Josse R, Adjide-Szmidt V, Avode DG, Dumas M. Seroprevalence of cysticercosis in the lacustrian community of Vekky, Atlantic district (Benin). Bull Soc Pathol Exot. 1996;89(1):24-9.

40. Noor Azian MY, Hakim SL, Sumiati A, Norhafizah M. Seroprevalence of cysticercosis in a rural village of Ranau, Sabah, Malaysia. Southeast Asian J Trop Med Public Health. 2006:37(1):58-61.

41. Gomes I, Veiga M, Embirucu EK, Rabelo R, Mota B, Meza-Lucas A, et al. Taeniasis and cysticercosis prevalence in a small village from Northeastern Brazil. Arq Neuropsiquiatr. 2002;60(2-A):219-23.

42. Phongluxa $K$, Xayaseng V, Vonghachack Y, Akkhavong K, van Eeuwijk $P$, Odermatt P. Helminth infection in southern Laos: high prevalence and low awareness. Parasit Vectors. 2013;6:328

43. Mengistu A, Gebre-Selassie S, Kassa T. Prevalence of intestinal parasitic infections among urban dwellers in southwest Ethiopia. Ethiop J Health Dev. 2007:21(1):12-7.

44. Yamasaki H, Araki K, Lim PK, Zasmy N, Mak JW, Taib R, et al. Development of a highly specific recombinant Toxocara canis second-stage larva excretorysecretory antigen for immunodiagnosis of human toxocariasis. J Clin Microbiol. 2000:38(4):1409-13.

45. Jacquier P, Gottstein B, Stingelin Y, Eckert J. Immunodiagnosis of toxocarosis in humans: evaluation of a new enzyme-linked immunosorbent assay kit. J Clin Microbiol. 1991;29(9):1831-5. 
46. Genta RM. Predictive value of an enzyme-linked immunosorbent assay (ELISA) for the serodiagnosis of strongyloidiasis. Am J Clin Pathol. 1988;89(3):391-4.

47. Koosha S, Fesharaki M, Rokni MB. Comparison of enzyme-linked immunosorbent assay and indirect immunofluorescence assay in the diagnosis of human strongyloidiasis. Indian J Gastroenterol. 2004;23(6):214-6.

48. Centers for Disease Control and Prevention: Diagnostic procedures. http://www. cdc.gov/dpdx/diagnosticProcedures/serum/antibodydetection.html. Accessed 10 June 2016.

Submit your next manuscript to BioMed Central and we will help you at every step:

- We accept pre-submission inquiries

- Our selector tool helps you to find the most relevant journal

- We provide round the clock customer support

- Convenient online submission

- Thorough peer review

- Inclusion in PubMed and all major indexing services

- Maximum visibility for your research

Submit your manuscript at www.biomedcentral.com/submit
Biomed Central 